\title{
O papel das professoras alfabetizadoras no desenvolvimento da entoação
}

\author{
Rosicleide Rodrigues Garcia \\ Universidade de São Paulo (USP), São Paulo, São Paulo, Brasil \\ prof.rosicleide@outlook.com \\ http://orcid.org/0000-0001-9857-961X
}

DOI: http://dx.doi.org/10.21165/el.v47i1.1957

\section{Resumo}

Em 2015, por meio da análise de $\mathrm{F}_{0}$, isto é, da frequência fundamental, e utilizando a metodologia desenvolvida pelo Projeto ExProsodia, Garcia verificou que o processo entoacional diferencia-se entre uma pessoa alfabetizada e aquela que não o é. A diferença aparece na finalização da entoação, pois o tom final (TF) e o tom médio (TM) apresentam médias semelhantes quando o entrevistado apresenta baixo grau de escolaridade, algo que é notavelmente diferente aos que possuem mais anos de estudos. Logo, pensando nesse contraponto, decidiu-se analisar quando a finalização começa a sofrer mudança, já que crianças de 3 a 5 anos costumam trazer a mesma característica de alguém desfavorecido educacionalmente. Para isso, buscaram-se gravações de professoras alfabetizadoras da primeira série do ensino fundamental em situações de sala de aula e em entrevista, e o resultado prévio desse estudo é que elas podem produzir uma finalização plagal quando estão em contato com os alunos e a finalização autêntica quando estão na entrevista. Sendo assim, percebe-se que há uma espécie de child-directed speech relacionada à entoação utilizada nos primeiros anos do ensino fundamental.

Palavras-chave: fonologia; entoação; processo de alfabetização; child-directed speech.

\section{The role of literacy teachers in the development of intonation}

\begin{abstract}
In 2015, after analyzing the $\mathrm{F}_{0}$ - fundamental frequency - by using the developed methodology by ExProsodia Project, Garcia verified that the entoacional process is different from educated and non-educated people. The difference is on the finalization because of the ending tone (ET) and the medium tone (MT) have similar averages when the interviewer gets low education, and this characteristic is different from the educated people. For this, this study aims to verify when the finalization process starts to change, if three to five-years-old children used to have the same characteristic of a lower-educated person. For this, the research had observed alphabetic teachers from the first years of basic education in some situations: in the scholar room and in the interview. The result showed that teachers can claim a plagal finalization when they were talking to young people, but they used the authentic finalization in the interview. Therefore, we can realize that there is a child-directed speech related to the intonation in the basic scholarship level.
\end{abstract}

Keywords: phonology; intonation; alphabetization process; child-directed speech. 


\section{Introdução}

No processo de alfabetização e letramento, há diversos estudos relacionados à aprendizagem da criança. Nesses estudos, mostra-se o motivo de serem aplicadas determinadas metodologias de ensino para atingir a compreensão dos alunos e como a fonologia participa desse processo, conforme veremos a seguir.

No entanto, há poucos estudos observando como a fala de um profissional influencia a criança, e como o procedimento adotado em aula participa da formação da entoação do estudante. Essa análise torna-se importante, pois o desenvolvimento entoacional é imprescindível durante o ato de absorção do conteúdo que se quer passar. Em outras palavras, a partir da entoação da fala dá-se a interpretação correta do que está sendo dito, e isto faz com que o interlocutor entenda a intenção informacional. Por exemplo, uma frase como "tô com fome!" é tida como neutra numa leitura, porém, durante a fala, esse único período pode passar diversas informações, o que demonstra se a pessoa está irritada, queixosa, cansada, ou se está apenas brincando com uma situação.

No caso deste estudo, o objetivo é verificar a finalização utilizada pelas professoras em sala de aula do primeiro ano do ensino fundamental, ou seja, como é dada a queda da frequência fundamental na fala dessas pessoas. Isso se deve, pois, na tese de Garcia (2015), verificou-se que pessoas com baixo grau de escolaridade costumam utilizar a finalização plagal, ao contrário das demais que possuem a chamada finalização autêntica, conforme veremos no próximo item. Por isso, surgiu a necessidade de entendermos quando a diferenciação inicia-se na vida da pessoa que frequenta o ambiente escolar, já que, ao estudarmos a entoação de crianças de até 5 anos, a finalização plagal aparece.

Desta forma, por meio do estudo de $\mathrm{f}_{0}$, isto é, da frequência fundamental, das falas de crianças e professoras, aplicou-se a metodologia desenvolvida pelo Projeto ExProsodia $^{\circledR}$, e, por meio dele, esta análise mostrará que, nos primeiros anos, é mais comum o profissional aproximar-se da fala infantil, processo similar ao que ocorre com o uso do child-directed speech (CDS), conforme será explicado.

\section{A metodologia aplicada}

Para desenvolver a pesquisa, primeiramente foram selecionados alguns vídeos do site Youtube, 12 gravações de crianças entre 3 e 6 anos, para delas serem analisadas 24 frases. Os critérios utilizados foram: vídeos em que a criança dialogasse com pouca intervenção de adultos, espontaneidade, teor familiar ${ }^{1}$.

Quanto ao gênero dos participantes, não houve diferenciação entre meninos e meninas, pois a frequência costuma ser de $250 \mathrm{~Hz}$ para ambos os sexos (HONOROF; WHALEN, 2005; BRAGA; OLIVEIRA; SAMPAIO, 2011).

\footnotetext{
${ }^{1}$ Isso significa que foram preferidos os vídeos realizados em ambiente familiar que possivelmente foram divulgados entre seus amigos e parentes. Aqueles em que a criança possui um canal no site para divulgação pessoal foram ignorados por tratar-se de gravações praticamente comerciais. Entende-se que as crianças que participam desse tipo de atividade monitoram sua fala e fazem participação quase teatral, não se adequando aos princípios desta pesquisa.
} 
Em relação às professoras, foram analisadas 30 gravações de cinco professoras do $1^{\mathrm{o}}$ ano do ensino fundamental. Essas professoras participaram de um projeto municipal que tinha como objetivo divulgar suas práticas pedagógicas. Para isso, as falas das professoras foram gravadas em entrevista, em que explicavam suas metodologias, e em sala de aula. Logo, separaram-se 15 gravações de cada ambiente.

As gravações, com cerca de 15 segundos cada, foram editadas e segmentadas pelo programa Audacity 1.3.12 Beta (Unicode). A análise e a conversão da curva de frequência fundamental e da curva de intensidade para arquivos de texto foram realizadas pelo software Speech Filing System (HUCKVALE, 2008), e, por fim, medidas em MIDI (abreviatura de Musical Instrument Digital Interface) ${ }^{2}$; todas as demais análises foram feitas pelo aplicativo ExProsodia (FERREIRA NETTO, 2010). Obtidos os valores do tom médio e final, estes foram ponderados por meio da base de cálculo de testes estatísticos ANOVA (testes T e F).

O foco analisado foram os tons médios (TM) e os tons finais (TF) de cada informante para se verificar o tipo de finalização produzido. Conforme mencionado, a realização das finalizações dá-nos subsídios para determinar se o falante possui baixo ou alto grau de escolaridade. Segundo Ferreira Netto (2008), nossa fala divide-se em quatro elementos estruturadores: finalização, sustentação, foco/ênfase e acento lexical. Por meio desses elementos, calcula-se o tom médio utilizado pelo falante a partir da média dos valores válidos de $\mathrm{f}_{0}$. A finalização, por sua vez, é a queda gradual de $\mathrm{f}_{0}$. Essa queda demonstra os pontos de articulação de uma fala, produzindo a entoação mais marcante, daí chamada de autêntica. A plagal, no entanto, possui os valores de TF muito próximos do TM, o que mostra que a fala não é tão bem articulada quanto a primeira. Por isso, as pesquisas (FERREIRA NETTO, 2008; COSTA, 2011; BAZ, 2011; GARCIA, 2015) demonstram que a autêntica é uma finalização produzida por aqueles que possuem um grau de escolaridade maior, pois, quanto mais escolarizado for um sujeito, mais sua articulação tende a ser desenvolvida por entender de maneira explícita seu processo linguístico.

Por causa disso, torna-se mister verificar a finalização dos falantes escolhidos e estudar esse processo.

\section{A fonologia e a fonêmica no processo ensino-aprendizagem}

De acordo com Soares (2017), nas últimas décadas, alguns paradigmas têm orientado os estudos sobre a aprendizagem inicial da língua escrita: o psicogenético, o fonológico e a possibilidade de união dos dois. Segundo a autora,

[...] a criança, para aprender a ler e a escrever, vivencia um processo em que as relações entre as cadeias sonoras e seus significados vão sendo progressivamente reconhecidas como abstratas, enquanto as relações entre as cadeias sonoras da fala e da língua escrita vão se tornando cada vez mais claras. (SOARES, 2017, p. 190).

\footnotetext{
${ }^{2}$ O MIDI é uma tecnologia padronizada de comunicação entre instrumentos musicais e equipamentos eletrônicos, sendo, basicamente, uma partitura digitalizada. Eletronicamente, ela define as instruções de notas, timbres, ritmos, efeitos e demais características sonoras.
} 
Logo, atualmente as aulas nos $1^{\text {os }}$ anos costumam primeiramente trabalhar com o concreto, que é a realidade da criança: os profissionais trazem objetos do seu dia a dia, como nomes próprios do cotidiano dos estudantes, comidas e situações que lhe são rotineiras. A partir disso, começa-se o procedimento de reconhecimento das palavras, juntando-se a isso o processo fonológico, de modo que o aluno comece a criar esse nível de consciência, conectando os sons das palavras à sua representação alfabética.

A psicogênese de Ferreiro $(1986,1992,2010)$ menciona que o entendimento da criança se faz primeiramente por frases fonológicas - ou seja, uma cadeia contínua de sinais acústicos sem fronteiras estabelecidas ortograficamente (CUNHA; MIRANDA, 2009) -, perpassando por fases em que ela imitaria os sinais gráficos. De acordo com a autora, a fase de alfabetização divide-se em cinco níveis: primeiramente, a criança faz uso de garatujas, que seria a representação gráfica das letras por meio de desenhos. Na segunda etapa, a pré-silábica, começa-se a fazer uso de letras para representar a escrita, mas de forma arbitrária. Após, alcança-se o terceiro nível, chamado de silábico, quando se inicia a relação entre letra e sílaba, em que a criança escreve geralmente uma consoante para cada sílaba. No quarto, os fonemas começam a ter mais representatividade e sílabas completas já são produzidas, sendo o silábico-alfabético. E, por fim, estabelece-se a escrita alfabética, em que há o domínio da escrita. Desta maneira, ainda consoante com Ferreiro (2004, p. 146), "os níveis de conceitualização da escrita [...] se correlacionam com as capacidades de segmentação da oralidade disponíveis nesse momento do desenvolvimento".

Assim sendo, percebe-se que essa elevação de níveis se dá em ambiente escolar, pois o processo ensino-aprendizagem requer posturas e aplicações metodológicas de seus profissionais de forma a auxiliar a criação da consciência fonêmica em seus alunos. Ele será o responsável por iniciar o processo de isolamento fonético, de modo que o aluno compreenda a diferença entre "bola" e "cola", por exemplo.

Em 1994, Barros afirmou que professores alfabetizadores tendem a modificar o ritmo e a entoação da fala. Ao mesmo tempo, a autora reconheceu que, ao enfatizar as sílabas e os clíticos, os profissionais da educação podem comprometer os valores fonológicos. Isto é, os constituintes prosódicos são aprendidos naturalmente, durante o processo de aquisição da linguagem. Sendo assim, o natural é que as pessoas produzam sua entoação de acordo com o meio em que está inserido. Todavia, por haver a necessidade da prática da escrita, esses valores são modificados, o que implica a mudança intuitiva também dos elementos constitutivos da fala.

E, exatamente nesse contexto, notamos que o papel da professora alfabetizadora vai além de ensinar a ler e escrever, já que modifica a entoação para se aproximar daquela realizada por seus alunos, conforme veremos a seguir.

\section{Análise da entoação das crianças}

Como mencionado na metodologia, foram selecionados áudios de crianças de 3 a 6 anos. Medindo-os em MIDI, os resultados apresentados são os que seguem abaixo: 
Tabela 1. Comparação em MIDI dos tons médios e finais da fala de crianças de 3 a 6 anos

\begin{tabular}{l|r|r}
\hline \multirow{3}{*}{3 anos } & Tom Médio & \multicolumn{1}{|c}{ Tom Final } \\
\cline { 2 - 3 } & 59 & 58 \\
\cline { 2 - 3 } & 65 & 64 \\
\hline \multirow{2}{*}{ MÉDIA } & 66 & 67 \\
\hline \multirow{3}{*}{ anos } & $\mathbf{6 3}$ & $\mathbf{6 3}$ \\
\cline { 2 - 3 } & 63 & 64 \\
\cline { 2 - 3 } & 62 & 61 \\
\hline \multirow{3}{*}{ MÉDIA } & 59 & 60 \\
\hline \multirow{4}{*}{ anos } & $\mathbf{6 1 , 3}$ & $\mathbf{6 1 , 7}$ \\
\cline { 2 - 3 } & 64 & 61 \\
\cline { 2 - 4 } & 63 & 59 \\
\hline \multirow{2}{*}{ MÉDIA } & 64 & 60 \\
\cline { 2 - 4 } & $\mathbf{6 3 , 7}$ & $\mathbf{6 0}$ \\
\cline { 2 - 4 } & 66 & 65 \\
\hline \multirow{2}{*}{ MÉDIA } & 65 & 68 \\
\hline
\end{tabular}

Analisando a Tabela 1, percebe-se que os valores de TM e TF das crianças de 3 e 4 anos diferem-se minimamente, de modo que sua média é compatível, e o teste $\mathrm{F}$ demonstra que não há mudança significativa $(0,41 ; \mathrm{P}>0,05)$.

Em se tratando das crianças de 5 e 6 anos, por sua vez, vemos que se inicia o processo de diferenciação, com mudanças de 2 a 3 pontos. Logo, o teste $F$ traz uma mudança significativa $(0,003 ; \mathrm{P}<0,05)$.

Ao observarmos o gráfico individualizado, percebe-se como pode ser visualizado esse processo de articulação do TM e TF: 


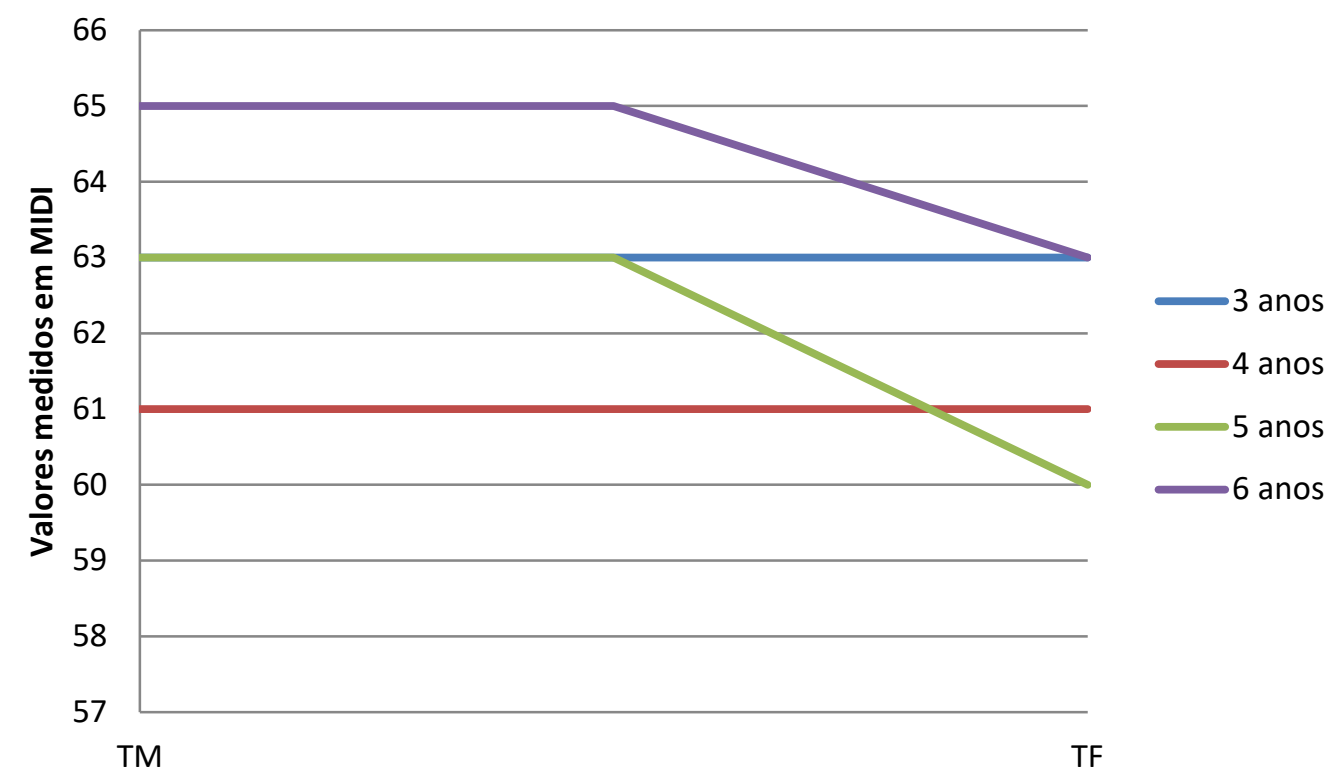

Gráfico 1. Comparação das médias de TM e TF das crianças de 3 a 5 anos

Logo, verifica-se que não há diferença entre o TM e o TF medido em MIDI entre crianças de 3 e 4 anos; e os dos estudantes de 5 e 6 anos é de 2 e 3 pontos, conforme visto na tabela abaixo:

Tabela 2. Observação das médias de TM e TF produzidas em entrevistas, e a diferença pontuada em MIDI

\begin{tabular}{c|c|c|c|c}
\hline & \multicolumn{2}{|c|}{ TM } & TF & Diferenças em pontos MIDI \\
\hline 3 anos & 63 & 63 & 63 & 0 \\
\hline 4 anos & 61 & 61 & 61 & 0 \\
\hline 5 anos & 63 & 63 & 60 & 3 \\
\hline 6 anos & 65 & 65 & 63 & 2 \\
\hline
\end{tabular}

Observando somente as características das finalizações das crianças, aparentemente a finalização autêntica começa a ser introduzida a partir dos 5 anos. Aos 3 e 4 anos, quando os alunos estão no Maternal, elas são apresentadas aos números e letras, considerando-se que podem estar no nível 1 e 2 (FERREIRO, 2010); e, aos 5 e 6, é dado início aos níveis 4 e 5 .

Deste modo, entende-se o motivo de a criança deixar a finalização plagal, trazendo, à sua fala, mais articulação e reconhecimento aos constituintes prosódicos.

\section{Análise da entoação das professoras de $1^{\circ}$ ano}

Seguindo o mesmo princípio da análise anterior, a tabela gerada obteve os resultados expressos a seguir. Os números referem-se às professoras (de 1 a 5 ), em situação de sala de aula e em entrevista. 
Tabela 3. Comparação em MIDI dos TM e TF da fala de professoras alfabetizadoras de $1^{\text {a }}$ série em situação de sala de aula (esquerda) e em entrevista (direita)

\begin{tabular}{|c|c|c|c|c|c|}
\hline \multicolumn{6}{|c|}{ PROFESSORAS ALFABETIZADORAS - $1^{\circ}$ ANO } \\
\hline Em aula & TM & TF & Entrevista & TM & TF \\
\hline \multirow{3}{*}{1} & 59 & 53 & \multirow{3}{*}{1} & 63 & 58 \\
\hline & 62 & 53 & & 59 & 55 \\
\hline & 60 & 54 & & 58 & 52 \\
\hline MÉDIA & 60 & 53 & MÉDIA & 60 & 55 \\
\hline \multirow{3}{*}{2} & 54 & 52 & \multirow{3}{*}{2} & 55 & 54 \\
\hline & 54 & 51 & & 56 & 49 \\
\hline & 53 & 51 & & 56 & 50 \\
\hline MÉDIA & 54 & 51 & MÉDIA & 56 & 51 \\
\hline \multirow{3}{*}{3} & 60 & 54 & \multirow{3}{*}{3} & 57 & 52 \\
\hline & 61 & 65 & & 57 & 52 \\
\hline & 61 & 58 & & 58 & 52 \\
\hline MÉDIA & 61 & 59 & MÉDIA & 57 & 52 \\
\hline \multirow{3}{*}{4} & 61 & 69 & \multirow{3}{*}{4} & 57 & 56 \\
\hline & 61 & 60 & & 58 & 52 \\
\hline & 61 & 55 & & 58 & 61 \\
\hline MÉDIA & 61 & 61 & MÉDIA & 58 & 56 \\
\hline \multirow{3}{*}{ 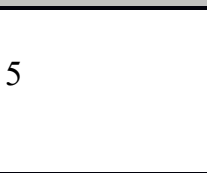 } & 59 & 58 & \multirow{3}{*}{5} & 57 & 53 \\
\hline & 57 & 58 & & 58 & 49 \\
\hline & 59 & 53 & & 54 & 50 \\
\hline MÉDIA & 58 & 56 & MÉDIA & 56 & 51 \\
\hline
\end{tabular}

Em geral, nota-se uma diferenciação entre elas. Em relação à professora 1, percebe-se que ela estabelece uma finalização autêntica: tanto em sala quanto na entrevista. Em ambos os casos, o teste $\mathrm{F}$ demonstra que as variações - em aula e em entrevista - são significativas $(0,12$ e 0,$43 ; \mathrm{P}>0,05)$.

No segundo caso, já se iniciam as diferenças entre sala de aula e entrevista entre o TM e o TF. Em aula, não houve diferenciação significativa $(0,5 ; \mathrm{P}>0,05)$, e na entrevista, $\operatorname{sim}(0,04 ; \mathrm{P}<0,05)$.

Ao estudarmos a oralidade da terceira professora, percebemos que não houve diferenciação significativa em ambas as situações $(0,01 ; \mathrm{P}<0,05),(0,000004 ; \mathrm{P}<0,05)$. $\mathrm{O}$ mesmo se dá para o quarto caso $(0$ e 0,$01 ; \mathrm{P}<0,05)$.

Em análise das falas da quinta professora, repete-se o ocasionado no primeiro exemplo: não há diferenciações significativas $(0,13$ e 0,$5 ; \mathrm{P}>0,05)$. Todavia, ao observarmos os números de maneira mais individualizada, geram-se os seguintes gráficos: 


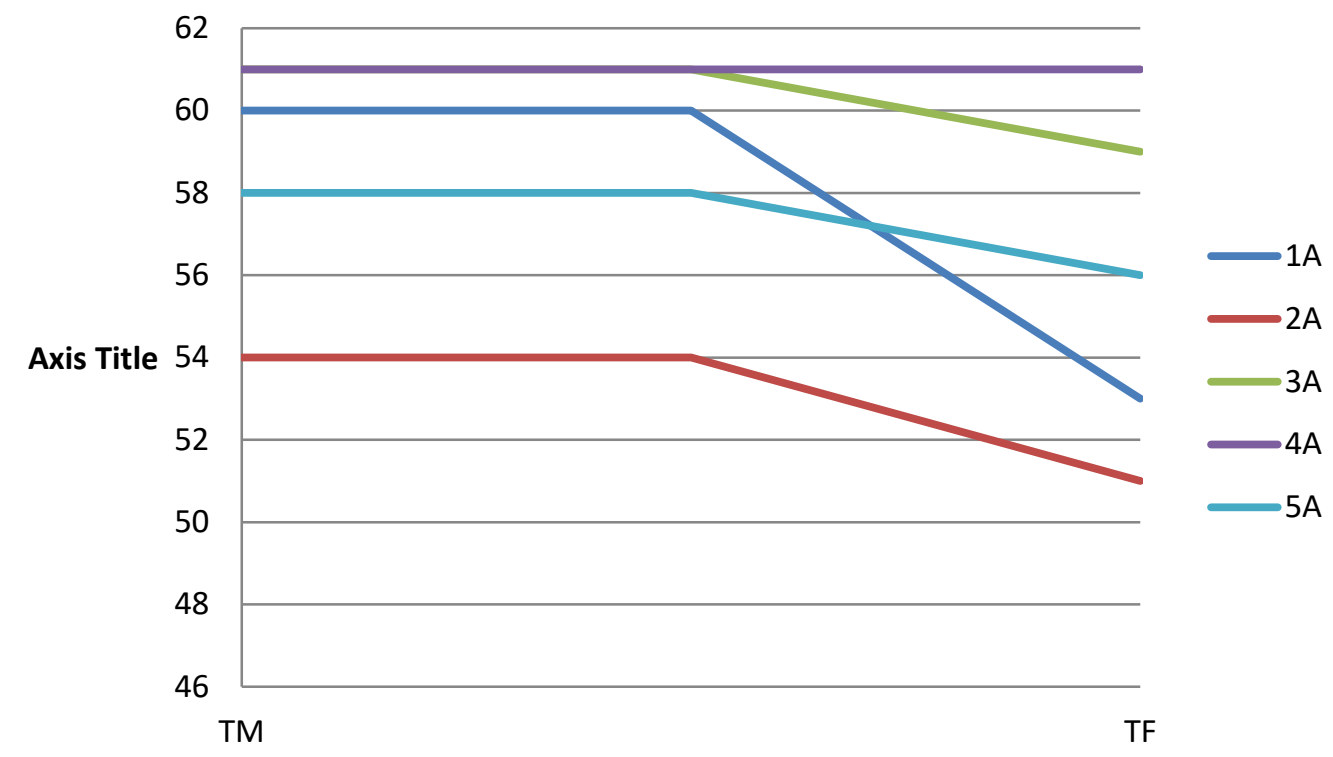

Gráfico 2. Comparação das médias de TM e TF em sala de aula com análise das 5 professoras

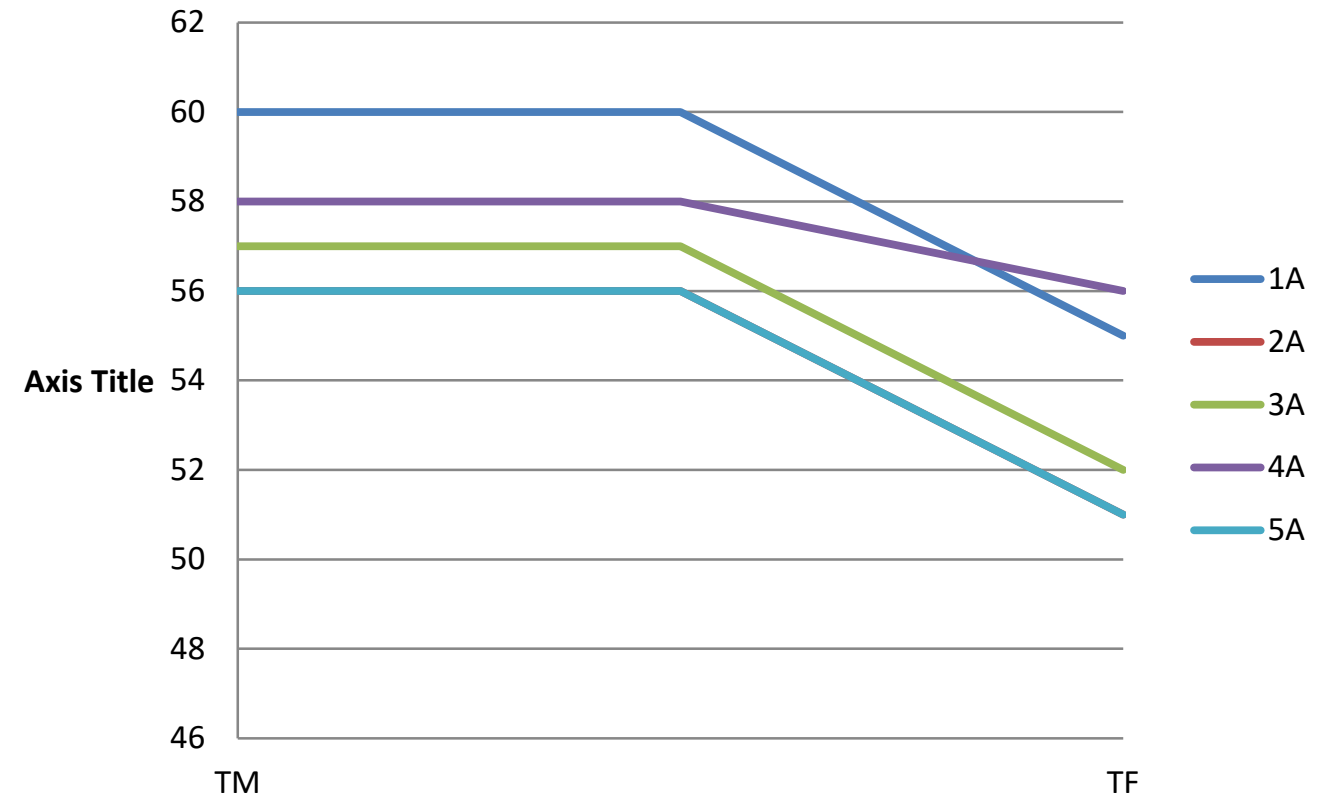

Gráfico 3. Comparação das médias de TM e TF em entrevista com análise de cinco professoras. Os casos $2 \mathrm{~A}$ e $5 \mathrm{~A}$ são idênticos, por isso $2 \mathrm{~A}$ ficou ocultado

Por meio dos gráficos, percebemos que 1A é a única que mantém o TF em declínio absoluto, produzindo a finalização autêntica. Percebe-se que a diferença do valor do MIDI é de apenas 2 pontos, pois, em aula, há 7 pontos de diferença e em entrevista, 5 .

Nas demais (excetuando 4A, em que a profissional produz a finalização plagal), embora seja visível a produção da finalização autêntica, percebe-se que os pontos de declínio são mais suavizados. Em geral, a finalização autêntica produzida em entrevistas, medida em MIDI, possui uma diferença de 5 pontos entre seu TM e TF; em sala de aula, a diferença é por volta de 3 pontos. 
Tabela 4. Observação das médias de TM e TF produzidas em entrevistas, e a diferença pontuada em MIDI

\begin{tabular}{c|c|c|c|c}
\hline Entrevista & \multicolumn{2}{|c|}{ TM } & TF & Diferenças em pontos MIDI \\
\hline $\mathbf{1 A}$ & 60 & 60 & 55 & 5 \\
\hline $\mathbf{2 A}$ & 56 & 56 & 51 & 5 \\
\hline $\mathbf{3 A}$ & 57 & 57 & 52 & 5 \\
\hline $\mathbf{4 A}$ & 58 & 58 & 56 & 2 \\
\hline $\mathbf{5 A}$ & 56 & 56 & 51 & 5 \\
\hline
\end{tabular}

Tabela 5. Observação das médias de TM e TF produzidas em sala de aula e a diferença pontuada em MIDI

\begin{tabular}{c|c|c|c|c}
\hline Em aula & \multicolumn{2}{|c|}{ TM } & TF & Diferenças em pontos MIDI \\
\hline $\mathbf{1 A}$ & 60 & 60 & 53 & 7 \\
\hline $\mathbf{2 A}$ & 54 & 54 & 51 & 3 \\
\hline $\mathbf{3 A}$ & 61 & 61 & 59 & 3 \\
\hline $\mathbf{4 A}$ & 61 & 61 & 61 & 0 \\
\hline $\mathbf{5 A}$ & 58 & 58 & 56 & 2 \\
\hline
\end{tabular}

Como podemos observar, os números sugerem que as professoras modificam sua entoação de acordo com o local em que estão. Vejamos que a diferença de entoação praticada pelas crianças de 4 e 5 anos é de 0 a 3 pontos, exatamente como ocorre na maioria dos exemplos aqui selecionados.

Tal fato faz-nos crer que as professoras tendem a modificar sua entoação equivalendo-se à das crianças. Dessa forma, vemos que, assim como ocorre com o childdirected speech (CDS) em que o adulto busca facilitar seu processo conversacional a fim de introduzi-lo à linguagem, o mesmo acontece em sala de aula das séries iniciais.

\section{Considerações finais}

Os estudos sobre aquisição de linguagem consideram que o CDS é utilizado pelos adultos por considerarem que a criança adquirirá com mais eficiência os eventos fonéticos de sua língua materna quando estes praticam a linguagem de modo diferenciado (LIU; KUHL; TSAO, 2003). De fato, os estudos comprovam que há a articulação das vogais e os pontos de frequência são diferenciais durante o diálogo com os bebês de maneira que a percepção do desempenho da fala pela criança seja mais clara.

Com esse breve estudo, percebemos que o mesmo acontece com a prática da alfabetização nas séries iniciais. Obviamente, o CDS não ocorre da mesma maneira que as demonstradas pelas pesquisas na área de aquisição de linguagem, já que, nos casos estudados, não há modificação de frequência por parte dos adultos, de modo que as falas se mantiveram de acordo com o esperado - as mulheres apresentam a frequência em torno de 150 a $250 \mathrm{~Hz}$. Todavia, é perceptível a variação entoacional de suas falas, fazendo com que, conforme demonstrado no artigo, a profissional tenda a se aproximar de seus alunos por meio do processo de finalização. 
De fato, talvez a nomenclatura child-directed speech aplique-se a esses casos de forma redirecionada, considerando a idade do público-alvo, seu objetivo e o ambiente em que ocorre, já que a prática da conversação em sala de aula não parece ser a mesma ao decorrer dos anos letivos. No entanto, o verbo "parecer" não é admitido neste tipo de ciência, por isso este artigo é apenas o primeiro passo para o estudo da entoação em sala de aula e para saber como esse procedimento influenciará estudos futuros sobre o processo de ensino-aprendizagem.

\section{REFERÊNCIAS}

BARROS, R. C. R. A natureza linguística da alfabetização: aspectos prosódicos. Signótica, Goiás: UFG, v. 6, p. 119-129, 1994.

BAZ, D. G. M. As relações entre entoação plagal e melodia de músicas populares paraguaias. 2011. 161 f. Tese (Doutorado em Língua Portuguesa) - Faculdade de Filosofia, Letras e Ciências Humanas, Universidade de São Paulo, São Paulo, 2011.

BRAGA J. N.; OLIVEIRA, D. S. F.; SAMPAIO, T. M. M. Frequência fundamental da voz de crianças. Rev. CEFAC, v. 11, n. 1, p. 119-126, jan./mar. 2009. Disponível em $<$ http://www.scielo.br/pdf/rcefac/v11n1/a16v11n1.pdf $>$. Acesso em: 19 ago. 2017.

CAGLIARI, L. C. Alfabetização \& linguística. 10. ed. São Paulo: Scipione, 2002.

COSTA, N. S. A. Variações entoacionais na língua portuguesa falada por mulheres guatós. 2011. 131 f. Tese (Doutorado em Língua Portuguesa) - Faculdade de Filosofia, Letras e Ciências Humanas, Universidade de São Paulo, São Paulo, 2011.

CUNHA, A. P. N.; MIRANDA, A. R. M. A hipo e a hipersegmentação nos dados de aquisição de escrita: a influência da prosódia. Alfa, São Paulo, n. 53, p. 127-148, 2009.

FERREIRA NETTO, W. Decomposição da entoação frasal em componentes estruturadoras e em componentes semântico-funcionais. In: IV CONGRESSO INTERNACIONAL DE FONÉTICA E FONOLOGIA, 2008, Niterói. Caderno de Resumos. v. 1. Niterói: UFF, 2008. p. 26-27.

ExProsodia. Revista da Propriedade Industrial - RPI, 2038, p. 167, item 120, 2010. Disponível em: $<$ http://revistas.inpi.gov.br/pdf/PATENTES2038.pdf $>$. Acesso em: 20 jul. 2017.

FERREIRA NETTO, W. et al. Finalizações de frase em leituras e frases espontâneas em PB. In: $57^{\circ}$ SEMINÁRIO DO GEL, 2009, Ribeirão Preto: UNAERP. Disponível em: $<$ https://www.academia.edu/2272648/Finalizacoes_de_frase_em_leituras_e_fala_espont anea no PB $>$. Acesso em: 08 jul. 2017.

FERREIRA NETTO, W.; CONSONI, F. Estratégias prosódicas da leitura em voz alta e da fala espontânea. Alfa: Revista de Linguística, São José do Rio Preto: UNESP, v. 52, p. 521-534, 2008.

FERREIRO, E. Com todas as letras. Tradução de Maria Zilda da Cunha e Sandra Trabucco Valenzuela. São Paulo: Cortez, 1992.

. Alfabetização em processo. São Paulo: Cortez, 1986. 
. Literacy development: psychogenesis. In: GOODMAN, Y. M. (Ed.). How children construct literacy: piagetian perspectives. Neward: International reading association, 1990. p. 12-25.

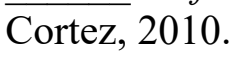

Reflexões sobre alfabetização. Tradução de Horácio Gonzales et al. São Paulo:

. Relações de (in) dependência entre oralidade e escrita. Tradução de Ernani Rosa. Porto Alegre: Artmed, 2004.

GARCIA, R. R. A entoação do dialeto caipira do Médio Tietê: reconhecimento, características e formação. 2015. 148 f. Tese (Doutorado em Filologia e Língua Portuguesa) - Faculdade de Filosofia, Letras e Ciências Humanas, Universidade de São Paulo, São Paulo, 2015.

HONOROF, D. N.; WHALEN, D. H. Perception of pitch location within a speaker's $\mathrm{F}_{0}$ range. Journal of the Acoustical Society of America. 2005. p. 2193-2200. Disponível em: $<$ http://www.haskins.yale.edu/Reprints/HL1385.pdf $>$. Acesso em: 19 ago. 2017.

HUCKVALE, M. A. Speech Filing System v.4.7/Windows SFSWin Version 1.7, em

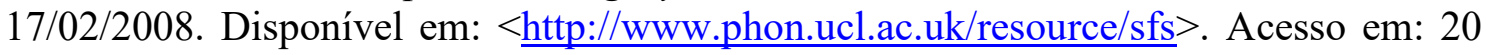
jul. 2013.

LIU, H. M.; KUHL, P. K.; TSAO, F. M. An association between mothers' speech clarity and infants' speech discrimination skills. In: Developmental science, 2003. p. 1-10. Disponível em: $<$ http://ilabs.washington.edu/kuhl/pdf/Liu_Kuhl_2003.pdf $>$. Acesso em: 19 ago. 2017.

SOARES, M. Alfabetização: a questão dos métodos. São Paulo: Contexto, 2017.

Recebido em: 30/08/2017

Aprovado em: 06/11/2017 